\title{
Measurement of Innovation: Where Do We Stand?
}

Lionel Artige

HEC - University of Liège, Belgium

\begin{abstract}
Innovation is widely considered as the main determinant of long-term economic growth. Despite this consensus, it is arduous to measure its economic effect at the firm and aggregate level. The objective of the present paper is to propose a critical examination of innovation indicators and measures of the economic impact of innovation. All available innovation indicators fall short of measuring innovation and its economic effect. However, the future could be more promising as enterprises are moving to a more quantitative management. The 'datafication' of their management could make available the information that innovation economists have long hoped for.
\end{abstract}

Keywords: innovation, measurement, patent, productivity, R\&D JEL Classification: C81, D24, E01, O30, O47

\section{Introduction}

Innovation is a very much used word nowadays in the media, in business or even in politics. It generally conveys a positive appreciation. The topic has also been very popular in the scientific literature. In fact, this popularity is relatively recent. According to the Scopus database, innovation has been a much studied topic since the 2000s (Table 1). Innovation is widely considered as the main engine of long-term income growth and changes within and across sectors. Nevertheless, innovation is not a smooth and universal economic process. It creates but also destroys value (Schumpeter, 1942). Some firms innovate a lot and others little. A few countries in the world are the main providers of innovations while many others are merely importers of these innovations.

Table 1

Occurrences of the word "innovation" in the title of scientific articles and books

\begin{tabular}{|lccccccccc|}
\hline & $1960-$ & $1970-$ & & $1980-$ & & $1990-$ & $2000-$ & $2010-$ & $1960-$ \\
& 1969 & 1979 & & 1989 & 1999 & 2009 & 2015 & 2015 \\
\hline \hline Articles & 271 & 844 & 2087 & 4112 & 11615 & 17015 & 33411 \\
\hline Books & 0 & 0 & 24 & 14 & 315 & 594 & 947 \\
\hline
\end{tabular}

Source: Scopus database

The endogenous growth literature has provided the theoretical mechanisms to show how technological innovation can influence the long-term rate of economic growth (Romer (1990), Helpman and Grossman (1991) and Aghion and Howitt (1992)). These mechanisms are based on monopolistic competition as suggested by 
Schumpeter (1942). The empirical literature has striven to provide evidence at the firm and the macroeconomic level.'

The empirical evidence is heterogeneous because empirical studies use different indicators of innovation. Most studies use proxies such R\&D expenditures or patent data to estimate the economic impact of innovation because identifying an observational indicator of innovation and measuring its economic value are notoriously difficult. The objective of this paper is not to review the empirical literature on innovation but rather to propose a critical synthesis on potential innovation indicators and measures of economic value of innovation.

The rest of the paper is organized as follows. Section 1 deals with the difficulty in defining innovation. Section 2 covers innovation accounting. Section 3 presents the measurement problems when productivity indicators are used to measure the economic effect of innovation. Section 5 concludes.

\section{Innovation: A Definition}

In order to measure innovation, it is necessary to define it. The purpose of a definition is to fix the limits describing the concept allowing its precise identification. As for the concept of innovation, this is challenging. If any infinitesimal departure from an existing product is an innovation, firms are likely to innovate constantly and the supply of products by firms is only composed of innovations. Measuring innovation would therefore not be an issue but the concept of innovation would be economically meaningless. If the definition is narrowed, then there will be innovating and non-innovating firms. The issue is then where to determine the separating line in order to identify the economically meaningful innovations. The definition of these limits has been very imprecise in the literature creating difficulties in identifying innovations and, hence, generating potential measurement errors.

\section{An abstract Definition of Innovation in Economics}

Etymologically, the word 'innovation' comes from Latin 'innovare', deriving itself from Latin 'novus' which means 'new'. 'Innovare' means 'to make an innovation in', 'alter', 'renew' or 'restore' (Oxford Latin Dictionary). The etymology tends to suggest that innovation brings some change over time. This change may be new to the latest generation (renewal) or to every generation (novelty). Innovation has been very popular in the media and the public in the last two decades. It is univocally viewed as a positive event or behavior. This positive value associated to innovation is fairly recent. Before the 19th Century, innovation was used in the religious and political language to denounce a threat to the established order (Godin, 2015). Then, innovation has become a condition for human progress. It is nowadays mainly used in the economic language.

Innovation is widely considered as the main source of economic growth and the rise in living standards. As a concept, innovation is not restricted to economics as many human activities involve innovation. Perhaps due to its pervasive use, definitions of innovation have proliferated, even within the field of business and economics. In the latter field, the multiplicity of definitions might be the result of the difficulty in observing objectively what an innovation is. The subjectivity in the identification of innovations is the main problem to measure them and their economic value accurately. In this paper, we will use the definition proposed by Greenhalgh and Rogers (2010):

\footnotetext{
I See Cohen (2010) and Hall, Mairesse, and Mohnen (2010) for surveys of micro and macro evidence.
} 
"Innovation can be defined as the application of new ideas to the products, processes, or other aspects of the activities of a firm that lead to increased value".

In other words, a firm innovates to increase value for its business-to-consumer clients (higher utility) or its business-to-business clients (higher profit) in order to increase value for itself (higher profit). If the value turns out to be negative, then the innovation is a failure.

This definition focuses on the economic value of innovation. Not every idea has an economic value. In economics, we are interested in the ideas affecting economic activities and possibly bringing higher living standards. Obviously, innovation is not the exclusivity of firms. Households, NGOs and public administrations can realize innovations bringing higher economic value to individuals and the society as a whole. However, there is generally no market value to measure these innovations. This is the reason why we generally focus on firms' innovations. Moreover, because of market incentives, firms are the main innovators in market economies.

\section{How to Identify Innovation in Markets?}

Then the question is: how to make this definition operational to identify and quantify innovations? When firms innovate, they change the supply of goods and services. The supply can be changed in two ways: quantitatively and qualitatively. When a firm increases the quantity of a same product, it changes the supply quantitatively. When a firm sells a new product, it changes the supply qualitatively. Innovation is precisely a qualitative change in the supply of goods and services. In order to measure the economic value of an innovation, it is necessary to distinguish the quantitative and the qualitative changes in the value added of the firm and, therefore, identify what is really new in its supply. This is challenging but crucial to provide an operational definition of innovation.

It may be argued that, from year to year, a firm always adjusts its supply to the demand and hence modifies it qualitatively in a gradual way. Its goods and services one year are not exactly the same a year after but are not completely new either. If the qualitative change in the firm's supply cannot be considered as a binary variable, what is the threshold in the continuous scale from which the change in the supply qualifies as an innovation? Where is the frontier of novelty? The Oslo Manual of the OECD (2005) provides a vague answer by arguing for a "significant degree of novelty" or a "significant improvement" in the products and processes to qualify innovation. This is obviously subjective and, in addition, the novelty can only be evaluated by the insiders of firms who know best their products. Another difficulty is to set the geographical frontiers of novelty. Greenhalgh and Rogers (2010) emphasize the distinction between imitation (diffusion of innovation) and innovation. A product or process new to the world market is obviously an innovation. A product or process new to the domestic market is an innovation if they are non-tradable. For instance, some services may be innovative if they are restricted to the domestic market. However, a product or process new to the firm is merely an adoption of an innovation introduced by another firm. It is the diffusion of an innovation but not an innovation.

The technical and geographical limits introduced to distinguish across products in the firms' supply are relevant but imprecise. This lack of precision generates a subjective appreciation about what an innovation is and, as a consequence, potentially large measurement errors. 


\section{Measurement of Innovation}

Measurement of innovation requires identifying an innovation indicator and a method to account or estimate the value of the innovation and its economic effect. As already mentioned, innovation creates and destroys value. Therefore, the value of an innovation is not equal to its economic effect. Moreover, innovation can have externalities for other firms. In what follows, we proceed by distinguishing the value of an innovation and its economic impact on the firm and the economy as a whole. Then, we relate the profit generated by innovation to labor productivity, which can be considered as an innovation indicator. Finally, we point out the problems of measuring labor productivity when the supply of products changes qualitatively over time.

\section{The Economic Value of Innovation}

Firms innovate to make their supply of products (goods or services) more attractive to the customers (final consumers or other firms). Any product's attractiveness will depend on its price and its desirability. A process innovation seeks for higher efficiency, which contributes to lowering the price of an existing product while a product innovation seeks for product differentiation and high consumer desirability of the new product. Lower price and high consumer desirability should lead to more sales and, possibly, more profits for innovating firms. If not, the innovation is a failure. The value created by an innovation is equal to

$$
V_{i}=q_{i}-c_{i}
$$

where $v_{i}, q_{i}$ and $c_{i}$ are, respectively, the nominal net value, the nominal sales revenues and the nominal cost of innovation $i$. The cost of innovation is the production costs of the innovation and, in addition, the expenditures on research and development. This cost thus includes expenditure on capital, labor and intermediate consumption associated with the innovation. If $V_{i} \geq 0$, then the innovation is a success.

\section{The Economic Effect of Innovation}

The value $V_{i}$, which is included in the firm's total profit, is rarely observable because the firm does not have to report it in its accounts. Values generated by old and new products are aggregated in the firm's accounts. Nevertheless, the calculation of the value $V_{i}$ would not be sufficient to measure the economic effect of innovation. If innovation creates value, it also destroys it as Schumpeter (1942) emphasized it. Even within a single firm, a new product can make an old one obsolete, simultaneously creating and destroying economic value. Therefore, the economic effect of an innovation cannot be equated to the sole value of the innovation. The economic effect of an innovation is the net value between the value created and the value destroyed. Then, the question is how to pin down this net value created by an innovation in the firm's accounts? Profit per worker seems to be the relevant variable. A successful innovation should increase the net profit per worker. The perworker profit function of a firm is

$$
\frac{\pi}{L}=\frac{p y-w L}{L}
$$

where $\pi$ is nominal profit, $p$ is the output price, $y$ is the real gross value added, $w$ is the average nominal wage and $L$ is the labor force. Therefore, profit is the remuneration of capital. If innovation is successful, nominal profit per worker should increase, i.e., the nominal gross value added per worker should increase faster than 
the average nominal wage. In other words, the effect of innovation on nominal profit per worker is positive, ceteris paribus, if the following derivative is positive:

$$
\frac{d(\pi / L)}{d i}=\frac{d(p y / L-w)}{d i}>0
$$

To remove the effect of the variation in prices over time, we calculate (3) in real terms. Therefore, the effect of innovation on real profit per worker is positive if

$$
\frac{d(\pi / p L)}{d i}=\frac{d(y / L-w / p)}{d i}>0
$$

Equation (4) makes clear that the two sources from which innovation can increase real profit per worker are real labor productivity and the wage-output price ratio. In other words, the net value created by innovation can channel through labor productivity or/and market power. In a perfectly competitive environment, in which the wage-output price ratio is given, real profit per work increases if real labor productivity rises. In a non-perfectly competitive market structure, real profit per worker depends on the change in labor productivity and in the degree of competition. If the output price goes up for a given wage, the firm increases its market power and adds a markup on its profits. Schumpeter (1942) argued that the two sources of profits are not independent. The decrease in the wage-output price ratio, due to a temporary market power, is necessary to cover the cost of innovation, which eventually leads to an increase in real labor productivity. If competition is perfect, there will be no markup and no return to cover the cost of innovation. For the imitating firm, real profit per worker depends on the two same sources but the cost of innovation is reduced or even null in some cases. This firm benefits from a positive externality.

Although the two sources of profits due to innovation are theoretically well identified, it is not easy to observe them in the firms' accounts because changes in real labor productivity and the wage-output price ratio can be affected by other causes than innovation. Therefore, in econometric studies, it is necessary to control for these other potential causes when one wants to measure the economic impact of innovation.

\section{Measurement of Productivity When Firms Innovate}

An additional difficulty in measuring innovation is to calculate the change in the real labor productivity when firms innovate. The calculation of the variation in productivity requires taking the change in prices into consideration. When a firm introduces a new product, there is no old price for it. This creates an additional potential error in the measurement of innovation.

Measurement of Productivity with Invariant Product Quality Let firm $A$ produce a single product. At time $t$, labor productivity of firm $A$ is

$$
\frac{P_{A, t} Q_{A, t}}{L_{A, t}}
$$

Where $P_{A, t}$ is the unit price of the product produced by firm $A, Q_{A, t}$ is the quantity produced and $L_{A, t}$ is the labor force employed by firm $A$. The expression (5) is an indicator of the labor productivity level, which is measured in nominal terms. At $t+1$, firm $A$ keeps on producing the same good. The variation in labor productivity is equal to

$$
\frac{\frac{Q_{A, t+1}}{L_{A, t+1}}}{\frac{Q_{A, t}}{L_{A, t}}}=\frac{1+\rho_{A, t+1}}{1+\mu_{A, t+1}}
$$


Where $\frac{1+\rho_{A, t+1}}{1+\mu_{A, t+1}}$ is the real variation in labor productivity between $t$ and $t+1, \rho_{A, t+1}$ is the labor productivity nominal growth rate and $\mu_{A, t+1}$ is the rate of variation in the selling price of firm $A$ 's product between $t$ and $t+1$. The real growth factor of labor productivity can be decomposed as follows:

$$
\frac{1+\rho_{A, t+1}}{1+\mu_{A, t+1}}=\frac{1+g_{A, t+1}}{1+n_{A, t+1}}
$$

Where $g_{A, t+1}$ is the growth rate in the quantity of firm A's product manufactured and $n_{A, t+1}$ is the growth rate in the labor force used by firm $A$ between $t$ and $t+1$. We can observe that the measure of real labor productivity growth depends on the measure of price inflation. If prices are overestimated, then productivity will be underestimated and vice versa. In all cases, the variation in labor productivity measures a variation in the production quantity. In the case of a single good, there is no reason to mismeasure prices. Therefore, calculating productivity growth is straightforward and accurate.

\section{Measurement of Productivity with Changing Product Quality}

It is now assumed that firm $A$ innovates between time $t$ and $t+1$. The quality of its product changes between the two time periods. Therefore, the quantities $\left(Q_{A, t}\right.$ and $\left.Q_{A, t+1}\right)$ and prices $\left(P_{A, t}\right.$ and $\left.P_{A, t+1}\right)$ do not refer to identical products. If productivity growth is measured as the nominal indicator deflated by the price variation, i.e. $\frac{1+\rho_{A, t+1}}{1+\mu_{A}, t+1}$

$\overline{1+\mu_{A, t+1}}$, then the choice of the production deflator is crucial. There are in fact two situations: the products are either identical or different between $t$ and $t+1$. In the former case, the change in quality is considered as insignificant and in the latter it is assumed to be significant.

- If the change in quality is considered as not "significant"

If we consider that the change in quality (innovation) introduced by firm $A$ is not significant, then we can assume that the products are identical and proceed as previously, i.e., consider that the price of the product at time $t$ is the initial price of the product at time $t+1$. Then, the variation in labor productivity measures a variation in the production quantity.

- If the change in quality is considered as "significant"

If we consider that the change in quality (innovation) introduced by firm $A$ is not significant, then wan cannot longer assume that the products between $t$ and $t+1$ are identical. We have to make an assumption on the initial price of the new good, which must be different from the price of firm A's product at time $t$. In all cases, the variation in labor productivity measures a variation in the production quality. Labor productivity in this situation is likely to be imperfectly measured.

\section{Conclusion}

There is no doubt that firms innovate to increase their profits. Measuring the economic impact of innovation is important because innovation creates but also destroys economic value, firms and jobs. Then, what is the contribution of innovation to income growth? This is difficult to answer because innovation is very complex to measure. This paper examines the causes of this difficulty and reviews the alternative indicators used in the literature. If these indicators have allowed to improve of our understanding of the innovation process, they have serious limitations. One improvement has been brought by innovation surveys although the potentially inaccurate answers and the bias in the collected data are serious concerns. This 
paper argues that big data could provide a breakthrough in this measurement complexity. Management of firms will increasingly be quantitative and dataficated. If security of the data is properly guaranteed, then it could be easier to extract detailed information on firms' innovations.

\section{References}

1. Aghion, P., Howitt, P. (1992): "A Model of Growth through Creative Destruction," Econometrica, 60(2), 323-351.

2. Cohen, W. M. (2010) "Chapter 4 - Fifty Years of Empirical Studies of Innovative Activity and Performance," In Handbook of the Economics of Innovation, Vol. 1, Ed. By B. H. Hall, and N. Rosenberg, Vol. 1 of Handbook of the Economics of Innovation, Pp. 129 213, North-Holland.

3. De Sola Price, D.J. (1963) "Little Science, Big Science," available at: http://www.andreasaltelli.eu/file/repository/Little_science_big_science_and_beyond. pdf $(08 / 05 / 2016)$

4. Edwards, K. L., Gordon, T.J. (1984) "Characterization of Innovations introduced On the Us Market in 1982: Final Report", Futures Group; Reproduced By Ntis.

5. Godin, B. (2015) "Innovation Contested: The Idea of Innovation over the Centuries", Routledge.

6. Greenhalgh, C., Rogers, M. (2010) "Innovation, Intellectual Property and Economic Growth", Princeton University Press.

7. Griliches, Z. (1979) "Issues In Assessing The Contribution Of R\&D to Productivity Growth," Bell Journal Of Economics, 10(1), 92-116.

8. Hall, B. H., Jaffe, A.B., Trajtenberg, M. (2002) "Patents, Citations and Innovations: A Window On The Knowledge Economy", chap. The Nber Patent-Citations Data File: Lessons, Insights, and Methodological Tools, Pp. 403-460. Mit Press.

9. Hall, B. H., Mairesse, J., Mohnen, P. (2010) "Chapter 24 - Measuring The Returns To R\&D," In Handbook Of The Economics Of Innovation, Volume 2, Ed. By B. H. Hall, and N. Rosenberg, Vol. 2 of Handbook of the Economics of Innovation, Pp. 1033 - 1082. North-Holland.

10. Helpman, E., Grossman, G.M. (1991) "Innovation and Growth in the Global Economy", The Mit Press, Cambridge, Ma.

11. Mairesse, J., Mohnen, P. (2010) "Chapter 26 - Using Innovation Surveys for Econometric Analysis," In Handbook of the Economics of Innovation, Volume 2, Ed. By B. H. Hall, And N. Rosenberg, Vol. 2 of Handbook of the Economics of Innovation, North-Holland, pp. $1129-1155$.

12. OECD (2005) "Oslo Manual. Guidelines for Collecting and Interpreting Innovation Data", Paris, 3rd Edition Edn.

13. Pavitt, K., Robson, M., Townsend, J. (1987) "The Size Distribution of Innovating Firms in the UK: 1945-1983", Journal of Industrial Economics, pp. 297-316.

14. Romer, P.M. (1990) "Endogenous Technological Change", Journal of Political Economy, pp. 98.

15. Schmookler, J. (1966) "Invention and Economic Growth", Harvard University Press.

16. Schumpeter, J. A. (1942) "Capitalism, Socialism and Democracy", New York: Harper \& Row, pp. 381.

\section{About the author}

Lionel Artige is Professor of Economics at HEC - University of Liège (Belgium). He is the Program Director of the Master in Economics at HEC and also co-director of the Liège Competition and Innovation Institute (LCii), a research centre specialized on competition and innovation issues. His research interests are innovation, competition and economic growth. Author can be contacted at lionel.artige@ulg.ac.be. 